\title{
Positive Bilanz - mit leichtem Dämpfer
}

\author{
Nach drei Messetagen schloss die diesjährige Parts2clean mit einer positiven Bilanz bei
}

Ausstellungsfläche und Qualität der Messekontakte. Dennoch musste die Messe nach den

Rekordjahren 2013 und 2014 nun einen leichten Besucherrückgang verzeichnen.

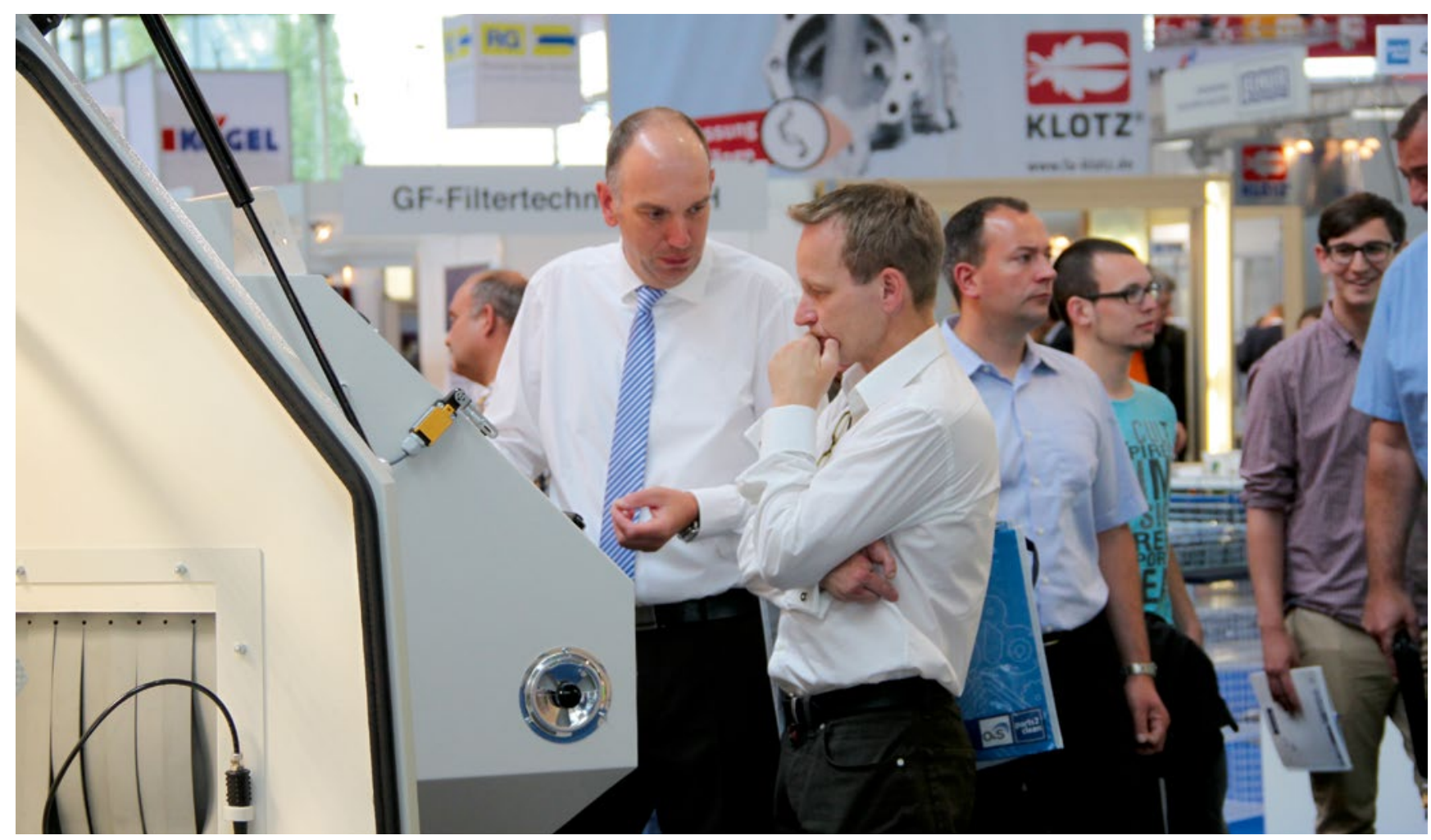

Aach den drei Messetagen der Parts2clean - der internationalen Leitmesse für industrielle Teile- und Oberflächenreinigung in Stuttgart konnte die Deutsche Messe AG als Veranstalter ein positives Fazit ziehen: „Die Messe ist aus sich heraus stabil und stark", bilanzierte Olaf Daebler, Geschäftsleiter der Parts2clean. Insgesamt präsentierten 254 Unternehmen aus 15 Ländern bei der 13. Auflage der Fachmesse neue, weiterentwickelte sowie bewährte Produkte und Dienstleistungen. Sie belegten eine Nettoausstellungsfläche von knapp 6800 Quadratmetern, was einem Plus von rund drei Prozent entspricht. Dennoch kamen weniger Besucher. Rund 4100 Fachbesucher zog es in diesem Jahr auf das Stuttgarter Mes- segelände, fast 1000 weniger als 2013 (in 2014 zogen die parallel veranstalteten Fachmessen Parts2clean und O\&S 8460 Besucher an). So manche Aussteller zeigten sich unzufrieden über das geringere Besucheraufkommen. Ein weiterer Diskussionspunkt lag in dem frühen Termin der Messe im Jahr und den von einigen Ausstellern bevorzugten Terminwechsel der Messe in den Herbst.

Überzeugen konnte die Messe vor allem durch die fachliche Qualifikation und hohe Entscheidungskompetenz der Besucher. 89 Prozent gaben in der Besucherbefragung an, in betriebliche Entscheidungsprozesse eingebunden zu sein. Die Fachbesucher waren aus insgesamt 25 Ländern an- gereist. Der Anteil ausländischer Besucher lag bei 20 Prozent. Die stärksten Besuchernationen waren die Schweiz, Österreich, Frankreich und Italien, gefolgt von Spanien und Großbritannien. Rund ein Drittel aller Besucher nutzte die Gelegenheit um ihr Reinigungswissen durch die Vorträge im Fachforum zu intensivieren. Auch die Guided Tours haben sich etabliert. Die geführten Touren zu 37 ausgewählten Unternehmen nutzten insgesamt deutlich mehr Fachbesucher als zuvor im ersten Jahr. Der jährliche Veranstaltungszyklus der Messe soll weiterhin erhalten bleiben. Die nächste Parts2clean ist für den 31. Mai bis 2. Juni 2016 geplant und wird im Messeverbund mit der O\&S stattfinden. 